\title{
INTER-PROFESSIONAL RIVALRY IN NIGERIAN HEALTH SECTOR: A SEARCH FOR A POTENTIAL BEG IN NING
}

\author{
${ }^{1}$ Sal isu AI, ${ }^{2} \mathrm{H}$ auwa IK, ${ }^{2} \mathrm{~A}$ bubakar M A , ${ }^{2}$ Ramla F, ${ }^{1} \mathrm{M}$ ukhtar IG , ${ }^{1} \mathrm{~N}$ afisa NY \\ ${ }^{1}$ Department of Human Physiology, Faculty of Basic Medical Sciences, Bayero, University Kano \\ ${ }^{2}$ Department of Human Physiology, Faculty of Basic M edical Sciences, \\ Yusuf Maitama Sule University Kano
}

\begin{abstract}
Correspondences and reprint request to: D r Salisu AI, Department of Human Physiology, Faculty of Basic Medical Sciences, Bayero University Kano, PMB 301, Kano State, Nigeria.
\end{abstract}

Email: saibrahim.pys@buk.edu.ng

\begin{abstract}
Background: Inter-professional rivalry (IPR) in Nigerian health sector has become a common practice for over a decade dueto abuse of the existing laws and ethics governing theoperations of the professional cadres manning the health institutions in the country. This has led to incessant strikes by the different cadres in the hospitals across the country, thereby affecting the quality of services delivered by all thecategories of healthcarestaff. This study was aimed at identifying the initial source of the problem by interviewing thestudents of theFaculty of Basic Medical Sciences of Bayero University Kano (BUK) and that of Yusuf Maitama Sule University (YUMSUK) and those that have passed their examinations and joined the clinical and allied science departments in Bayero University Kano. The Faculty of Basic Medical Sciences is the initial confluent point whereall medical and students of allied sciences receive their training together especially in the first and second year of their training. M ethod: A random sampling method was used to select the subjects. Two hundred questionnaires were distributed but 139(69.5\%) students at various levels of training filled and returned the questionnaire. Results: Females constituted 62 (44.6\%), while the male were 77 (55.4\%). Those in level 4 and 6 dominated the study with $55(39.6 \%)$ and 41 (29.5\%) respectively. Medical students and students of Physiology program constituted $42(30.2 \%)$ and $23(16.5 \%)$ respectively. M ajority of thestudents $126(90.6 \%)$ chose their respective courses without external influence and $85(61.2 \%)$ believed that their course of study has a supportive rolein thehealth care system. Up to 63(45.3\%) believed thereis no superiority among the various courses of study. Of the factors fueling superiority feelings among students, 70 (50.4\%) did not provide any reason, while those that believe professional bodies encourage it constituted 40 (28.8\%), followed by teachers 11 (7.9\%) and students themselves 10 (7.2\%). Superiority feel ings lead to rival ry among the various programs as opined by $78(56.1 \%)$, chaos in the health sector 26 (18.7\%) and poor patients management 12 (8.6\%). Majority, 61 (43.9\%) believed that rivalry in health sector can be prevented by giving uniform opportunity to all professional group. Conclusion: It is clear that half of thestudentsinterviewed werenot aware of superiority feeling among the different programs of study. However, professional bodies rank first among the factors fueling superiority feeling during undergraduate training. Superiority feeling has negative effects on the heal thcaresystem, one of which is rival ry among the healthcare

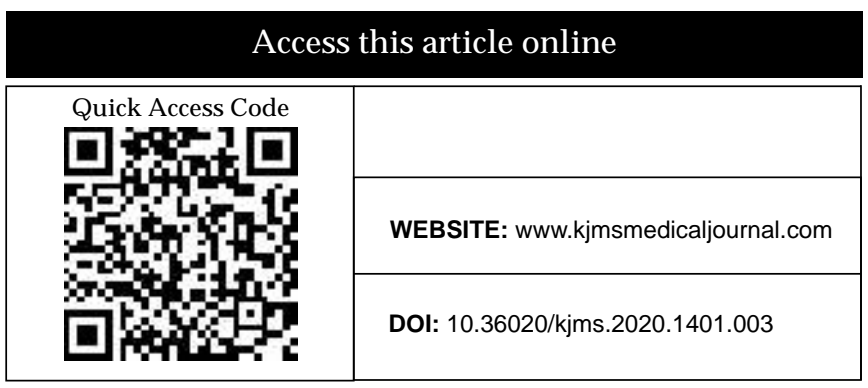
staff and it can be avoided by giving uniform opportunity to different professional groups.

KEY WORDS: Inter-Professional, Rivalry, Health Sector, Search, Potential beginning
\end{abstract}




\section{INTRODUCTION}

Nigerian health sector faced a lot of challenges for the past two decades due to conflicts among the healthcare professionals. The potential for con? ict or rivalry in the setting was signi? cantly higher because of multifaceted and regular interactions among health workers. ${ }^{1}$ Composition of healthcare workers in Nigerian setting includes; doctors, nurses, laboratory scientists, pharmacists, laboratory technician, community health workers, management personnel, social workers and other supporting staff. ${ }^{2}$ The health workforce crises in the country have taken quite unique, yet worrying, dimension in recent times. ${ }^{3}$ Most health workers have alleged that the Nigerian health system was designed to favor doctors mainly. ${ }^{4}$ Disputes over salaries, allowances, consultancy status and who heads the health sector have continued to emerge among different factions. ${ }^{3}$ Thealleged dominance of doctors over the years has encouraged other health workers to form the new group called the Joint Health Sector Unions (JOHESU). ${ }^{4}$ Distrust, dissensions and recurring conflicts among different professional groups in the health sector are now emerging. ${ }^{5}$ The aim of this study was to identify the probablebeginning of inter professional conflicts in Nigerian health sector by engaging students of Faculty Basic Medical Sciences and those that have crossed to the Clinical and Allied Science Departments after completing their pre-clinical training on common problems leading to IPR in Nigerian health institutions. The study will providevital information regarding these problems and may suggest possiblewaysto remedy them.

\section{MATERIALSAND METHOD Study Sites}

Thestudy was conducted in four different faculties; three of which are located in Bayero University, Kano; faculties of Basic Medical Science, Allied and Clinical Sciences and the fourth is that of Basic Medical science located at Yusuf Maitama Sule University Kano (YUMSUK).

\section{Study design}

A descriptive cross-sectional study was employed using astructured self-administered questionnaire.

\section{Study Population}

The study population involved all the students in various departments of the four faculties. The Faculties of Basic Medical Sciences of BUK and YUMSUK have three different departments each (A natomy, Biochemistry and physiology). The Clinical sciences handled programs of Medical Bachelor, Bachelor of Surgery (MBBS) and Bachel or of Dental Surgery (BDS) respectively, while the faculty of Allied Sciences has five different departments: Medical Laboratory Science, Nursing, Optometry, Physiotherapy and Radiography.

\section{SampleSize}

Two hundred questionnaires weredistributed to all the students, concentrating on level four and six students as appropriate depending on the type of course of study. These students had crossed from the pre-clinical area and have become acquainted with the clinic departments. Only 139 (69.5\%)students completed and returned the questionnaires, hencerecruited for thestudy.

\section{Sampling M ethod}

A random sampling method was utilized using ballot papers. Those that picked up blank ballot paperswereexcluded from thestudy.

\section{Statistical analyses}

Data were analyzed using SPSS software (version 20). Results were presented as frequencies and percentages.

\section{RESULTS}

Sociodemographic characteristics of the participants

The proportion of male participants was slightly higher than that of the female participants. While male participants accounted for 77 (55.4\%), the females were only $62(44.6 \%)$ - table 1 . Majority of the participants were 400 and 600 levels students (39.6\% and $29.5 \%$, respectively), while 500 level students constituted theleast (0.7\%) - table2.

\section{Program-related characteristics of the participants}

Majority of the participants were medical students (MBBS) 42 (30.2\%) with students of Bachelor of Nursing Science constituting the least 2 (1.4\%). Considering distribution based on faculties, the 
basic medical science students were 49 (35.3\%), allied students $37(26.6 \%)$, whilethe clinical science students constituted 53 (38.1\%). This implies that there was comparable spreadin recruiting the participants - table 3. A bout $91 \%$ of the participants were not pressured by anybody intotheir program of study-table4.

Factors fueling superiority feeling among the participants

A bout half of theparticipants, $50.4 \%$, wereunaware of any factor fueling feeling of superiority among students training to be healthcare professionals. However, $28.8 \%$ believed that such feeling was fueled by various professional bodies - table 5 . Similarly, majority of the participants, $61.2 \%$, believed that their course of study in thehealth care team is supportiveas against 33.8\% that thought it is dominant - table 6. While majority of the participants ( $45.3 \%$ ) believed that therewas no need for superiority of onecourse of study over theother, a staggering $34.5 \%$ believed otherwise table 7 . The respondents identified inter professional rivalry, chaos in health profession, and poor patient management as some of the negative outcomes of feeling of superiority of one's program of study over theothers- table8.

The participants suggested giving uniform opportunities to all professional cadres, opening up leadership positions to all cadres, and rationalization of the various professional bodies as some of the ways of reducing inter-professional rival ry in the health sector - table 9.

Table 1: Gender distribution of the Respondents

\begin{tabular}{lll}
\hline Sex & Frequency & Frequency\% \\
\hline Male & 77 & 55.4 \\
Female & 62 & 44.6 \\
\hline Total & $\mathbf{1 3 9}$ & $\mathbf{1 0 0 . 0}$ \\
\hline
\end{tabular}

Table2: Level of study of theRespondents

\begin{tabular}{lll}
\hline Level of Study & Frequency (N) & Percent (\%) \\
\hline 2 & 27 & 19.4 \\
3 & 15 & 10.8 \\
4 & 55 & 39.6 \\
5 & 01 & 0.7 \\
6 & 41 & 29.5 \\
\hline Total & $\mathbf{1 3 9}$ & $\mathbf{1 0 0}$
\end{tabular}

Table 3: Distribution of Respondents based on Programs of Study

\begin{tabular}{lll}
\hline Programme & Frequency & Percentage \\
\hline Anatomy & 14 & 10.1 \\
BDS & 11 & 7.9 \\
Biochemistry & 12 & 8.6 \\
BMLS & 11 & 7.9 \\
MBBS & 42 & 30.2 \\
Nursing & 2 & 1.4 \\
Optometry & 3 & 2.2 \\
Physiology & 23 & 16.5 \\
Physiotherapy & 12 & 8.6 \\
Radiography & 9 & 6.5 \\
\hline Total & $\mathbf{1 3 9}$ & $\mathbf{1 0 0 . 0}$
\end{tabular}

NB: MBBS = Medical Bachelor, Bachelor of Surgery $\mathrm{BDS}=$ Bachel or of Dental Surgery

Table4: Choiceof Course/ Program of study

\begin{tabular}{lll}
\hline Response & Frequency & Percent \\
\hline Self & 126 & 90.6 \\
Parent & 05 & 3.6 \\
Friends & 01 & 0.7 \\
Others & 07 & 5.0 \\
\hline Total & $\mathbf{1 3 9}$ & $\mathbf{1 0 0 . 0}$ \\
\hline
\end{tabular}


Table 5: Factors fueling Superiority feeling Among Table 9:Ways to prevention rival ry in the healthcare Students team

\begin{tabular}{lll}
\hline Factors & Frequency & Percent \\
\hline Students & 10 & 7.2 \\
Teachers & 11 & 7.9 \\
Professional Bodies & 40 & 28.8 \\
Society & 3 & 2.2 \\
Others & 5 & 3.6 \\
Blanks & 70 & 50.4 \\
\hline Total & $\mathbf{1 3 9}$ & $\mathbf{1 0 0 . 0}$ \\
\hline
\end{tabular}

Table6: Roles of Courseof study in thehealth care team

\begin{tabular}{lll}
\hline Role of program & Frequency & Percent \\
\hline Supportive & 85 & 61.2 \\
Dominant & 47 & 33.8 \\
I don'tknow & 06 & 4.3 \\
Blanks & 01 & 0.7 \\
\hline Total & $\mathbf{1 3 9}$ & $\mathbf{1 0 0 . 0}$ \\
\hline
\end{tabular}

Table 7: Whether Superiority feeling should been couraged among different courses of study

\begin{tabular}{lll}
\hline Response & Frequency & Percent \\
\hline Yes & 48 & 34.5 \\
No & 63 & 45.3 \\
I don'tknow & 12 & 8.6 \\
Blanks & 16 & 11.5 \\
Total & $\mathbf{1 3 9}$ & $\mathbf{1 0 0 . 0}$
\end{tabular}

Table 8: Effect of superiority feeling among the variouscourses/ programs

\begin{tabular}{lll}
\hline Response & Frequency Percentage \\
\hline $\begin{array}{l}\text { R i val r y a mong } \\
\text { variousprogram }\end{array}$ & 78 & 56.1 \\
$\begin{array}{l}\text { Chaosin theheal th sector } \\
\text { Poor patient management }\end{array}$ & 26 & 12 \\
$\begin{array}{l}\text { in thelong run } \\
\text { Others }\end{array}$ & 8.6 \\
Blanks & 08 & 5.8 \\
\hline Total & 15 & 10.8 \\
\hline
\end{tabular}

\begin{tabular}{lll}
\hline Response & Frequency & Percentage \\
\hline $\begin{array}{l}\text { By giving uniform } \\
\text { opportunity to all } \\
\text { professionals }\end{array}$ & 61 & 43.9 \\
& &
\end{tabular}

By giving leadership $28 \quad 20.1$ role of a particular program in the health sector

By rationalization of 30 various professional groups

\begin{tabular}{lll} 
Idon'tknow & 09 & 6.5 \\
Blanks & 11 & 7.9 \\
\hline
\end{tabular}

\begin{tabular}{lll}
\hline Total & 139 & 100.0
\end{tabular}

\section{DISCUSSION}

This study has interviewed undergraduate students of four faculties consisting of two basic medical sciences, Allied and Clinical science faculties in two universities located in Kano state, on the probable reasons leading to interprofessional rival ry in the Nigerian health sector. Ninety-one percent of the students chose their courses of study without any interference from anybody. This signifies that external influence plays fewer roles in the choice of course of study among the students interviewed. Although it has been known since decades that choice of course by clinical science students had been mainly due to people's interest in the course, Heikkila. ${ }^{6}$ In other studies some students make their professional career choice due to share influence from family, prestige attached to a particular course, and the need to help others. ${ }^{7}$ Other factors in other studies include; high societal status and the urge to serve the sick patients. With regards factors fueling superiority feeling among different programs of study, this study found that $50 \%$ of those interviewed lack awareness on the factor leading to superiority feeling among them, this indicates that majority of the students were not indoctrinated by their parents/ relations at hometo show superiority on their course of study over their colleagues reading other courses.29\% admitted that professional bodies show superiority feelings on 
students of different professional affiliations during ward rounds and at various levels of interactionsin thelaboratories, pharmacy unitsand other points of interactions within the hospital setting. This implies that feeling of superiority among students start to manifest after coming into contact with different professional bodies. This supports the work of Omisore et al., ${ }^{9}$ who documented that IPR was mainly caused by influence from professional bodies as opined by highest percentage of respondents in their work even though, their cohorts were health workers not undergraduate students. $8 \%$ of the students incriminated their teachers at various levels both at pre-clinical and clinical areas in fueling the superiority feelings aboveother specialties, thereby relegating others and pampering those along their lineage. Teachers should be effective role models; with high standards of clinical competence, excellence in clinical teaching skills and should have humanistic personal qualities. ${ }^{10,}{ }^{11}$ Of the students interviewed across the ten different departments/ programs run by these faculties, $61 \%$ believed that their course of study plays a supportive role in the health care team, while 34\% believed that their respective courses play a dominant role in the health care team, which is in line with the work of Omisore et al., ${ }^{9}$ among the healthcare professionals who documented that, there has been struggle for dominance among the health professionals as they receive full training in the art of patient care. Majority of those with dominance feeling in this study were those studying clinical courses(M BBS and BDS) students, probably due to the high number of those interviewed compared to the rest of students in other programs. In response to the necessity of having superiority feelings by those studying one course over the others, most, $45 \%$ expressed negative opinion on that, while $34 \%$ admitted "Yes". It means that some of the students have tendency to portray that behaviour later in life. On further questioning on whether the superiority feelings could be avoided 51\% admitted "yes", while $37 \%$ thought otherwise. It is therefore clear that most of the respondents were opposed to superiority feelings among themselves and those that had chosen to do so may hardly change in the future. Considering the fact that half of the respondents were opposed to the idea of superiority feeling among them, theproblem can be mitigated before the students graduate from the university through effective mentoring by level coordinators, heads of departments and deans of the respective faculties. Hence there is the need of teaching the relevant ethics along the edicts establishing each professional disciplineright from undergraduate level in order to avoid rancour among the healthcare professional in the future. Adverse effects of superiority feeling among students include; rival ry among various programs of study as opined by $56 \%$ of therespondents, chaos in the health sector in later life $18.7 \%$ and poor patient's management $8.6 \%$. Thissupportsthework of Onoka ${ }^{12}$ who documented that crises in health care have prevented optimal heath care delivery to Nigerian populace, sinceit hinders cooperation and teamwork among the various professional groups. Responses obtained from the students on ways to avoid rival ry in a heal thcare team have shown that $44 \%$ were of the opinion of giving uniform opportunity to all professional groups during training and after. The respondents believed this will improve performance at work and will also lead to better care for patients. $22 \%$ believed that rationalization of positions among the professional groups would help to reduce IPR among them, while 20\% suggested assigning a leadership role to a particular cadre would help reduce IPR in the healthcaresector.

\section{CONCLUSION}

Professional bodies rank first among the factors fuelling superiority feeling during undergraduate training. Superiority feeling has negative effects on the heal thcare system, one of which is rival ry among the healthcare staff and it can be avoided by giving uniform opportunity to different professional groups.

\section{RECOMMENDATIONS}

1. Inserting the enabling laws/ edits establishing theprofessional bodies into the curriculum of study for the various programs right at pre-clinical departments to help thestudents understand their area of jurisdiction to avoid over stepping their bounds. 
2. Mentor-mentee structure should be strengthened in all the faculties to help guide students on what is expected of them 4 . during training and also when they start practicing in their fields of specialization in later life.

3. Teachers/ lecturers should focus more on quality training rather than cloning the egocentered professionals who will add no value but rather compounds problems in thehealthcaresystem.

Government must ensure strict application of the laws and punish culprits at all the stages of training and practice whenever a valid case is established so as to serve as deterrent for those with similar minds of spoiling the health care system.

\section{REFERENCES}

1. Swansburg RC, Swansburg RJ (eds). Introduction to Manegement and Leadership for nurse $M$ anagers 3rd edition. Jones and Bartlett. Canada 2002.

2. (MHWHN). Teamwork, ProfessionismAnd Effective Health Care Delivery In Nigeria Being Paper Delivered At The $2^{\text {nd }}$ Annual Mhwun Guest LectureOf The Medical \& Health Workers' Union At Sheraton Hotels \& Towers, Abuja On April 11, 2013. Http:/ / Solidarityandstruggle.Blogspot.Co m/ 2013/ 04/ Teamwork-ProfessionismAnd-Effective.Html. A ccessed On 4/ 11/ 2019

3. AdeloyeD, Rotimi AD, Adenike $A O, A$ sa A, Adedapo A, Muktar G, Jacob K, Opele OO, Alexander I. 2017. Health workforce and governance: the crisis in NigeriaHuman Resources for Health volume 15, Article number: 32

4. Alubo $\mathrm{O}$, Hunduh V. Medical dominance and resistance in Nigeria's health care system. IntJ Health Serv 2017; 47(4):778-794.

5. JOHESU press release on the NMA strike and the imminent crisis in the health sector [cited 2016 September 09]; A vailable from: http:/ / www.medicalworldnigeria.com/ 20 14/ 07/ johesu-press-release-on-the-nmastrike-and-the-imminent-crisis-in-thehealth-sector\#.V86VjpgrLIU. Accessed on 06/ 12/ 2019
6. HeikkilaTJ, Harri $H$, JukkaV, Tiina $A$, Hannu $H$, Sentero K, IrmaV, MarkkuS, Kari $M$. Factors important in the choice of a medical career:a finish national study. 2015. J Med Edu, 15, 169.

7. Mchugh SM, Corrigan MA, Sheikh A, Lehane E, Broe P, Hill AD. A study of the factors inflencing school- going students considering medical career. N atl Center for Biotech inf 2011; 9(4), 191-194.

8. Sonu G, Federica A, N onita D, N eetu S, Dirk R. What motivate medical students to select medical studies: A systematic Literature review. BMC Med Educ2018; 18(1):16.

9. Omisore AG, Adesoji RO, Abioye-Kuteyi EA. Interprofessional Rivalry in Nigerian Health Sector: A Comparison of Doctor and other Health workers View at a secondary care. SA GE Journal 2017; 38(1), 9-16.

10. Passi V, Johnson S, PeileE, Wright S, H affert $\mathrm{F}$, Johnson N. Doctor Role Medeling in Medical Education BEME Guide No. 27. J Med Teach 2013; 35(9).

11. John G, Clyde AD, Anne G, Phil C. what makea good clinical students and teachers? and exploratory study. J Med Edu 2015; 15 (1).

12. Onoka C. Patients suffer as Nigerian healthcare workers continue a strike, who cares? 2010. Nigeria HealtWatch, http:/ / www.nigeriaheal thwatch.com/ 201 $0 / 08 /$ patients-suffer-as-nigerianhealthcare.html. Accessed on 12 August 2018.

Cite this article as: Salisu AI, H auwa IK, A bubakar MA, Ramla F, M ukhtar IG, N afisa NY., Inter-professional Rivalry In Nigerian Health Sector: A Search For A Potential Beginning. KJMS 2020; 14(1): 18 - 23. 